\title{
Success in the management of crowdfunding projects in the creative industries
}

Article

Accepted Version

Hobbs, J., Grigore, G. and Molesworth, M. (2016) Success in the management of crowdfunding projects in the creative industries. Internet Research, 26 (1). pp. 146-166. ISSN 10662243 doi: https://doi.org/10.1108/IntR-08-2014-0202 Available at https://centaur.reading.ac.uk/75559/

It is advisable to refer to the publisher's version if you intend to cite from the work. See Guidance on citing.

To link to this article DOI: http://dx.doi.org/10.1108/IntR-08-2014-0202

Publisher: Emerald

All outputs in CentAUR are protected by Intellectual Property Rights law, including copyright law. Copyright and IPR is retained by the creators or other copyright holders. Terms and conditions for use of this material are defined in the End User Agreement.

$\underline{\text { www.reading.ac.uk/centaur }}$

\section{CentAUR}


Central Archive at the University of Reading

Reading's research outputs online 


\section{Success in the Management of Crowfunding Projects in the Creative Industries}

Purpose - Crowdfunding has become a significant way of funding independent film. However undertaking a campaign can be time consuming and risky. This paper aims to understand the problems that small and medium sized productions companies may face when using this approach.

Design/Methodology/Approach - This study analyses 100 creative crowdfunding campaigns within the film and video category on crowdfunding website Kickstarter. Campaigns were analysed in relation to a number of variables, followed by an exploratory factor analysis to highlight the main factors contributing to crowdfunding success.

Findings - This study finds two key factors that contribute to crowdfunding success; 'Network Management' and 'Campaign Management'. The attributes of these factors lead us to question the long-term ability of crowdfunding to aid companies poorer in terms of time, financial and personnel resources, and therefore arguably in the greatest need of crowdfunding platforms.

Practical Implications - The findings provide insight to practitioners considering the crowdfunding approach and offers knowledge and recommendations so as to avoid what can be naïve and costly mistakes. The findings highlight that crowdfunding should not be considered lightly and can be a considerable investment of resources to be successful

Originality/Value - The individual analysis of crowdfunding campaigns undertaken allows for details and recommendations into the contributory factors of crowdfunding success particularly relevant to creative campaigns. The findings also allow the ability of crowdfunding to significantly aid upcoming or unknown creative talent to be put into question.

Keywords: Crowdfunding, Creative industries, Small to medium-sized enterprises, SME growth, Crowdsourcing, Monetisation, Engagement 


\section{Introduction}

Small to medium sized enterprises (SMEs) within the creative industries have a critical role to play in UK economic growth. In the UK 84 percent of creative companies employ fewer than 10 people, yet the industry as a whole accounts for 1.5 million jobs, £36bn of Gross Value Added, and 10.6 percent of the UK's export earnings, making it the third highest contributing industry (Skillset, 2012). Despite their importance to the economy, it is recognised that such SMEs struggle with access to resources (Tucker and Lean 2003; Hussain et al., 2006; Boyles, 2011), making it difficult for them to bring original content to market (De Buysere et al., 2012; Kenny and Broughton, 2012; Skillset, 2012). This may force them to focus on immediate commercial imperatives rather than the development of their own creative output (Powell and Ennis, 2007). These structural problems have been worsened by the 2008 financial crisis that led to more conservative attitudes from banks regarding SMEs (De Buysere et al., 2012). One result is that companies are seeking to do more with available resources (Fournier and Lee, 2009) and the 'crowd' has become regarded as a valuable source of surplus energy (Howe, 2008; Brabham, 2008) with the potential to add to jobs, innovation, and economic growth, and in the form of 'crowdfunding' a potential solution to problems with access to finance (Belleflamme et al., 2012; De Buysere et al., 2012).

\section{Objectives}

In this paper we analyse the factors leading to crowdfunding success, focusing on film campaigns as representative of one part of the creative industries, and a dominant category on crowdfunding platforms. Crowdfunding is now a significant way of funding independent film, with 10 percent of 2012's Sundance selection comprising of Kickstarter backed projects (Kickstarter, 2012a). However, with 60 percent of film campaigns being unsuccessful (Kickstarter, 2013), we aim to understand how small and medium sized production companies might achieve success with this approach. Press coverage has a tendency to be drawn to the success stories and the increasing number of creatives drawn to the method of fundraising, there is a danger that many may 'jump on the bandwagon' with out a real consideration of the resource investment required to carry out a successful campaign.

Our aims are to explore the factors that lead to a successful campaign and in doing so we end up questioning the long-term ability of crowdfunding platforms to aid those poorer in terms of time, financial and personal resources, and therefore arguably in the greatest need of these platforms. Our analysis leads to a paradox: the companies that might gain from such funding the most, may be the least likely in the long term to benefit from it. 


\section{Understanding Crowdfunding campaigns}

Jeff Howe (2009) coined the term "Crowdsourcing" to describe the phenomenon of utilising the crowds' surplus energy. The term defines the practice of initiating an open call (usually online) to an undefined network of people, for the provision of needed services, ideas or content. The basic premise is that the small input of many has greater value and impact than the large contribution of a few (Howe, 2009). Stemming from crowdsourcing we have witnessed the rise of crowdfunding, which utilises similar characteristics to collect small financial contributions from a large number of networked individuals, thus tapping the crowd's surplus finances rather than their surplus energy (Howe, 2009). In their study (Belleflamme et al., 2013, p6) define crowdfunding as: "an open call, mostly through the Internet, for the provision of financial resources either in the form of donation or in exchange for the future product or some form of reward to support initiatives for specific purposes". This highlights the exchange nature of Crowdfunding. Rather than a "free" donation, the practice usually involves making specific offers of goods and services in addition to the project offered, in return for funds.

Crowdfunding is in many ways not a new idea. For example, it can be traced back to the 1700s through the concept of microfinancing. One notable early example was the Irish Loan Fund, initiated by Jonathan Swift in order to provide credit to the country's poor; at the funds height, loans were being made to $20 \%$ of households (Hollis and Sweetman, 2011). Politicians and charities also have a long history of soliciting small financial donations in ways that mirror the practices utilised by crowdfunding. Internet based crowdfunding is however relatively new, and one of the first examples occurred in 1997 when fans of British rock group Marillion raised $\$ 60,000$ to finance a U.S. tour for the band. Since then, with the aid of online technologies we have seen a wealth of start-ups, new products, and original creative content come to market through the support of crowdfunding. To date there are over 450 crowdfunding platforms online (Massolution, 2012) taking contributions in different forms, including equity purchase, loans, donations or pre-orders (Belleflamme et al., 2012). We therefore have a system in flux, where little is known on how best to make it work and for which types of projects. As a result we see a variety of approaches, but this is potentially confusing and/or intimidating for those unfamiliar with it and possibly in need of the funds the most. SMEs in particular risk wasting what limited resources they have on approaches that may not work for them. 
The most recognised crowdfunding model, and our concern here, is the reward-based model. Here contributions are solicited in the form of donations and pre-orders in return for often non-monetary rewards (Belleflamme et al., 2012; Massolution, 2012). The model is used by prominent platforms like Kickstarter and Indiegogo that enable campaigners to present their idea in the form of an online pitch, alongside which a list of tiered rewards are offered in exchange for contributions. Campaigners then have a set period of time (usually 48 weeks) in order to meet their target financial goal. The popularity of such platforms has been accelerated by a number of standout successes, such as OUYA, an Android powered game console that raised $\$ 8,596,474$ in a month from 63,416 backers (Kickstarter, 2012b). Kickstarter actually claim that nearly half of the campaigns they host are successful (Kickstarter, 2013) seemingly promoting the approach as low risk and highly attractive compared to other types of financing. However, we should consider that a "serious" campaign that raises $\$ 10,266,845^{1}$ bears the same weight as a "joke" campaign that raises $\$ 16^{2}$ in Kickstarter's data. What is also unclear is how success should be defined, while we can determine whether campaigns have raised their target funds, it is less clear whether they successfully deliver on the project. Mollick (2012), for example, found that few projects deliver on time. Even the aforementioned OUYA faced backlash from early backers after failing to deliver all consoles before their retail launch date as initially promised (MacManus, 2013). Press stories about the bankruptcy of a successful campaigner (Markowitz, 2013) also offer stark reminders of crowdfundings risks, even when a project is successful. Despite this further complication, our interest here remains in how to manage crowdfunding campaigns, and to identify those factors that contribute to a successful crowdfunding campaign. However, we recognise that a potential reason for failure to deliver is the need for SMEs energies to be diverted away from work and towards the crowdfunding project itself. As we shall see, managing a successful campaign may be highly resource intensive.

Although the figures presented by Kickstarter suggest an attractive, almost 50:50 chance of success this likely masks very different odds for new projects. Despite reward-based models being represented by the majority of platforms (Massolution, 2012) it appears few other studies analyse them. Mollick (2012) uses data from nearly 47,000 Kickstarter projects of all types to identify the determinants of success or failure, with project quality and size of networks shown as key factors in success. However, the identification of these factors may

\footnotetext{
${ }^{1}$ E-Paper Watch, the most funded Kickstarter campaign ever raised \$10,266,845 from 68,929 backers. Accessed 30 January 2013. http://www.kickstarter.com/projects/597507018/pebble-e-paper-watch-for-iphone-and-android?ref=most-funded

2 A Campaign to raise funds for a pack of guitar stings. Given the affordability of the target goal, the campaign becomes a questionable use of Kickstarter. Accessed 30 January 2013 http://www.kickstarter.com/projects/354898629/no-strings-attached-get-it
} 
seem of limited value to potential campaigners who might already assume that a good project and lots of "fans" would be beneficial, yet lack knowledge of the complexities of what might work for their specific campaign. So whilst our study also proposes an analysis of successful drivers based on Kickstarter data, we aim to review aspects of networks and of campaign management in more detail. Mollick's (2012) study for example, uses the mere presence of video in a campaign pitch to determine higher quality. This judgement however disregards the quality of the said video and ignores other signals of quality such as pitch length, detail and passion. Advice from the crowdfunding platforms themselves also means pitch videos are becoming standard practice (Badour, 2011), thus questioning whether the presence of a video alone is enough to determine quality. Our focus is filmmaking campaigns, recognising that by narrowing down the focus, individual characteristics unique to each category may be identified.

\section{Crowdfunding and network management}

In comparison to other sources of funding, crowdfunding is said to generate small amounts of capital and as such contributions tend to stem from a campaigners family and friends (Mollick, 2012), or what is known as the First Degree Network (RocketHub, 2011). Recently however we have seen campaigners targeting larger amounts of capital, requiring campaigners to utilise their wider networks, defined as the Second Degree Network (friends of friends) and the Third Degree Network (strangers) (RocketHub, 2011). This combination of networks is akin to the balanced composition of strong and weak ties in a start-up's social capital that is argued to aid its innovation and performance (Pirolo and Presutti, 2010) and so represents a key factor in gaining financial support. The transition through networks is also similar to how financing (Hussain et al., 2006) and advice (Peltier and Naidu, 2012) are obtained through an SME lifecycle. In early stages SMEs rely heavily more on immediate networks (friends and family) before becoming transitioning to external sources as the firm ages Thus we may argue that newer companies are likely to find accessing the wider networks more difficult.

Transition through networks in crowdfunding is identified by Ordanini et al. (2011) and modelled as a three-stage process. Phase one is described as the "friend funding" stage, where an initial quick flow of investment from people directly connected to the campaign reaches approximately half the target goal. Friend funding therefore stems predominately from the campaigners first-degree networks, where the trust of personal connections accelerates initial funding. The second phase is described as "getting the crowd" and is 
argued to be the most challenging phase. In this stage the responsibility is on the campaigner to move visibility beyond the First Degree Network or risk of stagnation that may make the investment seem less attractive. For campaigns that are able to maintain momentum a third funding phase begins described as the "Race to be in" stage. This occurs when individuals with no original connection to the campaign sees the project is close to reaching its goal and are motivated by a fear of missing out.

Kuppuswamy and Bayus (2013) find a similar funding pattern in their study, arguing that crowdfunding campaigns suffer from a bystander effect, where a drop in support follows initial excitement in a project as backers assume others will provide the support. Bystander effect they argue is somewhat counteracted by a deadline effect as a campaign nears its the end, but they still advocate that campaigners must work to overcome stagnation in the middle phase. An implication here is the need to manage this temporal process throughout the campaign.

In summary, crowdfunding literature consistently argues for the importance of social networks as well as the effective management of these networks (Mollick 2012; Hui et al., 2013), which is also echoed by findings in the entrepreneurial literature (Molina-Morales and Martinez-Fernadez, 2010; Seghers et al., 2012; Durkin and McGowan 2013; Sigmund et al., 2013). For SMEs however this can prove difficult due to their resource poverty, which can mean their execution of, and ability to manage social networks is haphazard and informal (Gilmore et al., 2001; Franco et al., 2014), and lacks purposeful use (Durkin and McGowan, 2013). This may then lead to their ability to create sufficient networks being reduced.

\section{Crowdfunding and campaign management}

However, it also seems clear that the management of the campaign itself is important. Agrawal et al. (2011) suggest that the online mechanisms of crowdfunding and the ability to reach a wider set of consumers are key to crowdfunding success. However, the ability to harness these online mechanisms is missed (or possibly assumed) by many campaigners and a recent study on crowdfunding work states that the time, commitment and audience size needed is often underestimated (Hui et al., 2013). This is encapsulated by the crowdfunding approach being misunderstood as "free". Buysere et al. (2012, p18) for instance state: "No other investment form, be it debt or equity, can provide the benefits of pre-sales, market research, word-of-mouth promotion, and crowd wisdom without additional cost". However, Hui et al. (2013) warn against this perception that crowdfunding is an "easy" way to fundraise and argue that a campaign is a one to two year process, during which campaigners 
are often overwhelmed by the various commitments involved that are often outside their area of expertise. Over the course of a campaign their study argues that various campaign skills are required including publicist, accountant, project manager, and engineer.

Other studies confirm the complexity of campaigns. Research from entrepreneurial literature (Cardo et al., 2009; Payne et al., 2009) suggests that domain expertise and track record are important criteria in investment decisions as they help develop trust in the entrepreneurs capabilities. Providing evidence of track record can however be difficult for SMEs who may be new to market and a lack previous content precedence evidence their expertise can hamper access to resources (Tucker and Lean, 2003). Thus, first time projects may be more difficult to fund than those from experienced filmmakers due to difficulties in demonstrating track record.

Chen et al. (2009) further argue that the preparedness of entrepreneurs can positively impact funding decisions by presenting higher impressions of quality. Alongside preparedness, passion is also argued to help potential investors gain a more positive impression (Elsbach and Kramer 2003; Cardon et al., 2009). Here we see funders considering the people behind the project when the project itself remains ambiguous. This preparedness and passion towards the idea, is also argued to be important traits required in order to successfully carry out new ventures (Alstete, 2008).

Previous research has also found that campaigns that provide more updates raise greater sums of money (Labovitz, 2010) and are seen as an important part of the campaign management (Ward and Ramachandran, 2010; Kuppuswamy and Bayus, 2013; Xu et al., 2014). So skill in managing a campaign and a commitment to it are necessary.

In addition, Gerber et al. (2012) suggest that backers are now discerning when it comes to judgements of rewards in crowdfunding activity. In a series of interviews they identify "getting" and "buying" as words used by backers to describe their transactions, leading them to suggest crowfunding is motivated by consumer as well as philanthropic behaviour. From a campaigner perspective, offering value may seem difficult, as the overarching need is to profit from the rewards in order to have remaining funds to meet the projects purpose.

Hype and enthusiasm about the potential of crowdfunding may under-emphasise resource costs for the time and effort involved, the exact nature of which remains unclear and which is our focus here. From an SME perspective this issue means from the outset the undertaking of a crowdfunding project requires its campaigners to push their workload, possibly beyond the limits of their resources, something that the use crowdfunding is supposedly attempting to circumvent in the first place. 


\section{Methods and data analysis}

Our study aims to understand those factors that contribute to successful crowdfunding campaigns by examining difference between successful and failed campaigns.

In total we analysed 100 crowdfunding campaigns. Our study initially included 24 successful and 24 failed filmmaking campaigns undertaken on Kickstarter between December 2012 and February 2013. A further 26 successful and 26 failed filmmaking campaigns were selected between December 3 and December 7 2013, bring the total to 100 (50 successful and 50 failed). There is no difference in how the two datasets were collected. The second set of campaigns was selected to ensure a sample size of 100 cases that are well adequate for exploratory factor analysis (Fabrigar et al., 1999; Wesley et al., 2006). The selection of most recently ended campaigns ensured that data relating to the campaigners networks accurately pertained to the time the campaigns were run.

Kickstarter and other crowdfunding platforms make failed projects difficult to find ( $\mathrm{Pi}$, 2012). Our selection criterion for failed filmmaking campaign is whether the campaign has reached its target or not. Whilst Kickstarter display a browse-able directory of 'Recently Successfully Funded' campaigns, there is no similar function for 'Recently Unsuccessfully Funded' campaigns. Thus without prior knowledge or access to a failed campaigns URL they can be difficult to view. Campaigns in this study were therefore selected from the most recently ended campaigns within the "Film \& Video" sector at time of data collection. Recently ended campaigns were viewed in terms of whether or not they had reached their financial target. Unlike previous studies (Mollick, 2012) we individually examined the available information on each campaign relating to both the available networks, and the details of the campaigns themselves as presented on Kickstarter.

\section{Analysing campaign quality}

Analysis of campaigns was undertaken based on, reward quality and pitch quality. Analysis criteria for reward quality included level of choice and the tangible and intangible value offered (Table 1). Alongside this, the rewards value for money, geographic vulnerability (rewards requiring the backer to travel to a certain location), and influence of content precedence (for example a consideration of a rewards offering a phone call with an established versus and unknown filmmaker) were considered with ratings adjusted accordingly. 
In identifying the pitch quality (Table 2) we looked for evidence of passion and preparedness. For passion we looked for visual cues in pitch videos along with evidence of time already invested in the project. Preparedness considered the level of detail within pitch documents to give a coherent understanding of the project and considered the following: pitch video, evidence of content precedence, descriptive text about the project, explanation of fund use, consideration of the risks involved with the project, number of project updates or impressions of quality. In both cases the criteria were independently applied to a sample of campaigns to ensure consistent application.

\section{Exploratory factor analysis}

Campaigns were then analysed in relation to a number of variables (Table 3), an overview of each campaign is offered in Appendix 1 (successful) and Appendix 2 (failed). We considered the target set by the campaign organisers and the total amount raised as a result of the campaign (in \$US). This also gives us the goal percentage (Kickstarter allows campaigners to continue funding even after their goal has been reached, so this figure may exceed 100 percent). We considered the networks reached by campaigns, starting with the direct network size (DNS); a sum of those individuals directly connected to campaigners via personal social networks. We also looked at Social media connected to the campaign, including the number of "shares" on Facebook. We were then able to compare these networks with the number of campaign backers and financial goals of the campaign. We also looked at campaign search engine performance. Alongside the variables directly related to the operation of a campaigns network management and financial issues, reward quality and pitch quality were included in the analysis.

Before running an exploratory factor analysis to identify factors of successful crowdfunding campaigns, we provide the mean scores and standard deviation for each item (Table 4). Then preliminary analysis to control dimensionality of the significant factors contributing to successful crowdfunding campaigns was performed. Dimensionality was controlled by principal component analysis, with Varimax rotation and factor extraction according to MINEIGEN criterion (all factors with eigenvalues of greater than 1). Descriptive statistics show that research data was appropriate for factor analysis (KiaserMeyer-Olkin $=0,806$; Bartlett's Test of Sphericity $=414.134 ; \mathrm{p}=0.000<0,001$ ). Principal components analysis suggested two factors for the success of campaigns, which account for a cumulative 72.97 percent of the variation in the data. Table 5 reports the results of the 
principal component analysis, such as the remaining items and their factors loadings, explained variance by each factor.

Factor 1, labelled "Network management", integrates number of backers (0.90), number of search results (0.84), total raised (0.76) and number of shares (0.75). Here we see how successful campaigns exploit online networks to raise money. Factor 2, labelled "Campaign Management", integrates pitch quality (0.85), reward quality (0.82) and number of updates (0.60).

Table 6 shows the mean scores, standard deviations and corresponding t-tests for successful and unsuccessful campaigns. When comparing successful and failed campaigns, the analysis shows that the following variables are indeed predictors of success in crowd funding campaigns: number of updates, search results, Facebook shares, total amount raised, number of backers, reward quality and pitch quality. Here we see that successful campaigns effectively present campaigns, offer meaningful rewards and engage audiences throughout the campaign period. We now discuss these in more detail.

\section{Network Management}

Number of Backers

Unsurprisingly, successful campaigns attracted more backers than failed ones. Data from this study suggests that the number of backers should be equal to approximately one to two percent of the target goal, thus a $\$ 4,000$ target goal would require between $40-80$ backers. On average backers in relation to the target goal of successful campaigns was 1.7 percent compared to 0.4 percent for the failed. These figures may also allow us to suggest the network size required to reach a goal. Backers compared to DNS for campaigns in this study were between 1-5 percent; therefore we can tentatively suggest a DNS of 2,400 would be required to meet the $\$ 4000$ goal. If we then look at those campaigns with target goals close to $\$ 4,000$ we can see that the failed campaigns had DNS's under this figure while the successful campaigns were in excess (Table 6). This may suggest that the failed campaigns were over ambitious in terms of the funding goals they could achieve given their existing network and would imply that they need to build that network before committing to a campaign.

\section{Search Results}

First Degree Networks can only carry a campaign for the initial period before the Second and Third Degrees are required to reach a funding target (RocketHub, 2011; Ordanini et al., 2011; Kuppuswamy and Bayus, 2013). Campaigns may therefore fail due to a "build and they will 
come" mentality and an underestimation of the need for campaign marketing (Cohen, 2010; Hui et al., 2013). To determine the broader reach of a campaign the number of Google search returns were used. The successful campaigns search return $M d n=123.5$ were double the failed $M d n=50.0$. As well as emphasising the need to actively distribute a campaign beyond an initial circle of friends and family, these results may also allow us to suggest that the successful campaigns (and not just the project) were of higher quality. Blogs and news outlets are motivated by the need to offer content of value to maintain reputation and satisfy audiences (Jenkins et al., 2013) and are therefore more inclined to share campaigns of higher quality. Information and recommendations provided by these news sources can then subsequently influence the consumers purchase intentions (Hus et, al. 2012).

\section{Facebook Shares}

Contribution to social networks is motivated by a need to establish identity, gain respect and publicise expertise (Shao, 2009). Thus individuals are likely to share campaigns of higher quality to maintain these goals. The opinions of 'ordinary' consumers are found to be persuasive in the promotion of cultural offerings such as film and video discussed here (Chiou et, al. 2014), thus it becomes important to encourage the consumers to share and recommend campaigns. Our data shows that campaigners with a strong desire to get their campaigns "out there" are likely to share it multiple times through the campaigns duration and as a result Facebook shares for successful campaigns overwhelm that of the failed, with $M d n=394$ compared to $M d n=75$.

\section{Total raised}

Not only are successful campaigns meeting their target goals, in many cases they exceed these amounts, thus while total raised may appear as an obvious contributor of success, it is indicative of the factors outlined and further emphasises the importance of network management in order to successfully attain the target goals set. It also helps illustrate that campaigners must balance setting goals that not only cover budgetary requirements, but that are also achievable. The $M d n$ value of the successful campaigns DNS in relation to their target goal was 46.53 percent, while the failed campaigns were only 14.87 percent, suggesting the failed campaigns were over ambitious in terms of what their networks could achieve. This may mean crowdfunding should be considered in tandem with other sources of funding or as separate campaigns for separate stages of production (e.g. pre-production/postproduction). 


\section{Campaign management}

Pitch Quality

Artistic products like the filmmaking campaigns studied here are surrounded by ambiguity and uncertainness (Botti, 2000); being uncompleted entities means potential backers can only go on ideas conveyed by the campaigner. Thus the passion and preparedness of a campaigner can help reduce uncertainty and risk by increasing the impressions of quality (Cardon et al., 2009; Chen et al., 2009; Payne et al., 2009). From our pitch analysis we identified a number of common traits and difference amongst the campaigns.

Pitch Videos: The pitch video is becoming a common feature of crowdfunding campaigns, with their use widely advocated in advisory blogs and press (DesMarais, 2013; Rocket Hub, 2013). Pitch videos within filmmaking campaigns have a two-fold impact. Firstly they enable the campaigners to directly appeal to, and initiate relationships with their audience (Steinberg and DeMaria, 2012; RocketHub, 2013). However not every campaigner chooses to present a direct address within their pitch video. In opting not to address the audience campaigners loose the opportunity to express passion and emphasise why their creative vision must be fulfilled. From the campaigns we analysed, $15 \%$ of the failed campaigns choose not to present a direct address within the pitch video compared to $10 \%$ of the successful campaigns.

Secondly the pitch video provides space in which campaigners can present example video footage from the project or from previous work. This helps campaigners show previous content precedence and build trust in their skills as a filmmaker. This idea of content precedence is further discussed next.

Evidence Of Content Precedence: Cardon et al. (2009) suggest that domain expertise and track record are important criteria in investment decisions as they help develop trust in the entrepreneurs capabilities. Steinberg and DeMaria (2012) also argue that within crowdfunding campaigns evidence of established work is critical for backers to determine value. As argued earlier however, providing evidence of track record can however be difficult for SMEs and those new to market due to a lack previous content.

Of the campaigns studied, successful campaigns provided clear evidence of the their filmmaking capabilities demonstrating a strong professional or academic background. For example the "Lives In Transit" campaign run by the Global Lives Project, showed precedence with a set of 10 previous films which had achieved over 100,000 views, whilst 
the listed campaign founder David Evan Harris has previous precedence with institutes such as UC Berkley, Stanford, and Google.

Ambitious funding targets amongst the successful campaigns in particular were matched with more established and professional precedence and some campaigners also partnered with well-known personalities to give their campaigns extra credence. Filmmaker Aaron Lieber in his surf film campaign "Zero to Hero" for example, provides detailed background and examples of his previous surf films, but also partners with well-known surf personality Lakey Peterson. This gives the campaign that seeks to support the filmmakers first full-length film additional credibility and third-party certification (Agrawal et al., 2013).

Content precedence for failed campaigns was more limited with a number of campaigners seeking to fund their first significant film. The campaign "Leatherbound: A Kings Gambit" for example was its creators first feature length film. Despite this the campaigners offered little detail and no links to examples of previous work, leaving little to help build confidence in their abilities to fulfil their project. With this need for content precedence we can question crowdfunding's ability to aid unknown talent and upcoming talent, and suggest that crowdfunding might best be used once a filmmaker has already invested in establishing their identity. This again supports the idea that success in crowdfunding is often a long-term strategy rather than a quick fix solution to secure funds for a new project.

Detailed Text Description: Text descriptions allow campaigners to further elaborate on their project proposal. A well thought out and described pitch document shows the campaigner is well prepared and has taken time to invest in the project (Chen et al., 2009). Overall we found successful campaigns provided greater detail over the failed campaigns. Those campaigns that offered the greatest detail covered all aspects of the project from story, production, cast and crew, rewards and reasons for choosing crowdfunding. Providing sufficient detail is a major element of creating trust, which is a key concept in online purchasing (Hsu et, al. 2014). Trust directly affects the perceived risk of the transaction, relevant and up-to-date information can thus address any consumer uncertainty (Chen et al., 2009; Steinberg and De Maria, 2012, Hsu et, al. 2014).

Financial commitment is the key element of crowdfunding, thus a clear explanation of fund use becomes an important element of providing sufficient detail. Only 3 percent of successful campaigns failed to give an explanation of fund use, with a further 12.5 percent providing unclear explanations. This is in comparison to the failed campaigns where 11 percent gave no explanation and a further 17 percent were unclear. 
Building trust and showing preparedness through the text description continues in the required section of Kickstarter pitch documents titled 'Risks and Challenges', which ask campaigners to express any issues that may arise through the development of their project. Often this section appears rushed and overlooked by campaigners and our analysis found successful campaigns gave greater consideration to this section. Those who made the best use of this section openly expressed concerns and potential limitations of their projects, while also offering reassurance and potential solutions to these concerns.

Impressions of Quality: Through our analysis we also found successful campaigns gave higher impressions of quality, both in their pitch videos and the overall consideration of the pitch document and content precedence. Whilst we understand that such claims suffer from the risks of subjectivity and bias, we also find a higher number of successful campaigns provide evidence of external endorsement, either through an ambassadorial circle or press articles. This external endorsement may back up our claims of higher quality as they provide third-party backing (Agrawal et al., 2013).

\section{Reward quality}

Reward Overview: Rewards are argued to be one of the most important motivations for participating in crowdfunding (Kuppuswamy and Bayus, 2013). In filmmaking campaigns rewards typically range from a simple thank you, to more exclusive rewards like cast roles. Exclusive rewards like cast roles, and other rewards that afford the consumer some control (e.g. script feedback sessions, re-naming characters) work as they enable the backer to become a co-creator of project idea. Allowing such co-creation experiences enhances the consumer's engagement and relationship, and subsequently their intention to purchase and refer others (Blasco-Arcas et, al. 2013). We find a common behaviour in the construction of rewards is to have each tier offer a subset of rewards as the tier levels increase. For example, a backer opting for the $\$ 25$ price tier would receive the same as a $\$ 10$ backer with one or two extra rewards to account for the additional expense. Kickstarter allows campaigners to offer rewards at any price point between $\$ 1-10,000$, however we found the following tiers were most commonly used $\$ 10, \$ 25, \$ 50, \$ 100, \$ 250, \$ 500, \$ 1,000$ and $\$ 5,000$. The most commonly backed tier level is $\$ 25$ and this is where we tend to see the introduction tangible items, particularly DVDs. Of the 100 campaigns analysed 74 percent offered a DVD copy of the film, with the remaining 26 percent offering digital access (download/web link). Of this 74 percent, 72 percent offered DVDs between the $\$ 25-50$ tiers. Before the $\$ 25$ tier level 
rewards tend to be limited to thank you style rewards in various forms (e.g. via email, social media, or film credits). Other pre $\$ 25$ rewards include behind the scenes access to production material, and in a few cases (22 percent) tangible visual rewards (prints/postcards/stickers). This study found successful campaigns on average offered a greater range of rewards and provided higher quality reward offerings. We will now discuss further the findings of our reward analysis.

Content Precedence in Rewards: As well as influencing pitch quality we find content precedence may also affect reward quality. In our analysis we identify a number of campaigns (particularly failed) offered rewards that hold little value unless the proposed creative entity becomes a success, or, the filmmaker is already established. Rewards that fall within this bracket are those such as phone/Skype calls with the creators. If the director is an established personality the appeal of such rewards increases (Steinberg and DeMaria, 2012); the opportunity for aspiring filmmakers to have a one-to-one with Spielberg has inspirational value. Yet when the offer is $\$ 45$ for a 20 minute Skype call with an unknown US college student with little filmmaking experience we can question the rewards value and appeal.

Other rewards, which we may link to content precedence, include promotional links or sponsored credits. Such rewards are only valuable if the filmmaker can guarantee that it will be seen by a large number of individuals, much like the value of an advert increases with higher exposure (Novak and Hoffman, 2000). Therefore the promotional link offered by "Mario Warfare" holds greater value over other campaigns that provide similar offers, as the campaigners can refer to viewer figures in excess of $1,000,000$ based on their previous content precedence.

Value for Money: By comparing the rewards offered at different tiers and observing the number of backers opting for these tiers, we believe backers may be approaching crowdfunding with a 'shopping mentality' as they seek out value for money in their purchase decision. This notion has also been found in previous research, Gerber et al. (2012) for instance suggest that backers are aware of the exchange of value when browsing campaigns. We found numerous examples of difference between the value offered by successful and failed campaigns. At the $\$ 150$ tier level for example we can observe 'Mario Warfare' from the successful campaigns and 'Animal Justice League' from the failed. At this tier 'Mario Warfare' offers a host of rewards; A limited edition signed poster pack, An exclusive T-shirt, Signed DVD, Signed DVD of creators previous series, Exclusive online access to previews 
and behind the scenes footage and a website thank you credit. In comparison 'Animal Justice League' only offers a photo of the backer to appear on set in the final episode. The tangible items offered by 'Mario Warfare' alone have a value close to at least $\$ 100$, while the single reward offered by 'Animal Justice League' has no tangible value for the backer and is also subject to the campaigners previous precedence. Successful campaigns placed greater emphasis on offering "real" value to backers, with thought and creativity placed into the construction of rewards. As stated earlier rewards are one of the most important motivations for contributing towards a campaign, thus their construction should be a high priority in developing campaigns.

Geographic Vulnerability: Another factor we identified in rewards is "Geographic Vulnerability" (GV), which we use to describe rewards constrained by location, such as set visits or cast roles. While such rewards have a unique participatory element to them, they are constrained by the backer's locale, thus we must consider that GV potentially hampers the number of backers a tier may attract. We found both the successful and failed campaigns offered rewards hampered by GV, yet we also found the successful campaigns backed GV with tangible items and also sought to compensate for it. For example if we compare "Treasure Trapped" and "Love Demon" from the successful and failed campaigns respectively and look at the $\$ 400$ tier, we find "Treasure Trapped" compensates for GV by offering to travel to the backer (within Europe). Whilst in "Love Demon" potential backers are required to travel to the films set location. The "Zero to Hero' campaign provides us with a further example of GV reduction. The campaign has GV present at every tier from $\$ 100$ onwards, yet helps compensate in two ways. Firstly the filmmakers have a set date and location for the GV reward (film premiere), thus potential backers know at time of purchase whether travel is feasible. Secondly the film features a famous surfing personality, thus increasing the premiere's value when compared to campaigns where the filmmakers and actors are relatively unknown (Steinberg and DeMaria, 2012).

\section{Updates}

The updates section of a pitch allows campaigners to supply further project details and information on production progress. They also provide the impression of activity, showing the campaigners have the skill and commitment required to overcome risks of stagnation and push the campaign forward (Ward and Ramachandran, 2010; Kuppuswamy and Bayus, 2013; $\mathrm{Xu}$ et al., 2014). In our study we found only 3 percent of failed campaigns provided more 
than 5 updates during their funding time frame, with 29 percent not providing a single update. In comparison while 13 percent of the successful campaigns also did not provide any updates, 16 percent provided 5 or more.

\section{Conclusion and recommendations}

Filmmaking campaigns are often wrapped in ambiguity and uncertainness due to the various contingencies involved in the production process, for example a product specification is easier to imagine than the creative conclusion to a film and this means that approaches to film crowdfunding may be different from other successful campaigns. Our findings demonstrate internal structures and drivers of success, relevant to the filmmaking campaigns studied here, but with possible application to crowdfunding campaigns as a whole. What we have done is to identify the significance of a range of factors that increase the likelihood of success. Here crowdfunding is presented not as a quick fix solution to funding shortfall, but a significant investment of time and resources, which are not dissimilar to those required in traditional sources of funding that crowdfunding is proposed to circumvent. Thus our findings have both theoretical and practical implications that add to the existing body of crowdfunding work.

Firstly for those thinking about undertaking a crowdfunding campaign there are a series of practical considerations that are shown to be factor in a campaigns success. In order to build

the trust necessary to bridge any ambiguity Campaign management may be crucial to demonstrate the campaigners capabilities and address quality uncertainty. Campaign management requires campaigners to address pitch and reward quality and ensure backers remain updated through the duration of the campaign. Pitch quality and updates provide evidence of both passion and preparedness, which aid in developing backer trust and confidence. Rewards are a key motivation for backer contribution; we find campaigners should consider the value for money, avoid or compensate GV and consider their content precedence in the construction of rewards.

We also find Network management has an influence on success. Important factors in network management include number of backers, search results, Facebook shares and total raised. Within network management it is crucial that campaigners not only have an established audience they can reach out too, but also the skills and resources to reach outside there initial networks and spread their campaigns within wider circles. An implication here is that network management is required well before a crowdfunding campaign is even developed. It is also important campaigners understand the sums of money achievable in relation to their networks. 
Secondly, on a theoretical level our findings lend further support to previous studies (Mollick, 2012) that identify project quality and network sizes are important determinants of success. However the deeper individual analysis of each campaign allows us to provide greater details and recommendations of what contributes to these factors and in particular we note the importance of the 'management' of both the network and campaign, rather than merely the size of the network or quality of the project. We also highlight the influence of Geographic Vulnerability and Content Precedence in the construction of crowdfunding rewards, which to our knowledge are not previously identified.

These findings allow us to question the ability of crowdfunding to significantly aid upcoming or unknown filmmaking talent. Establishing each of the outlined factors requires resources, (in terms of time, finances and skilled personnel) over a sustained period, which individuals and SMEs face a continued struggle to provide (Boyles, 2011). Thus crowdfunding can be argued to succumb to the Matthew Effect (Merton, 1968; Mollick, 2012), where those who are already richer both in terms of identity, resources and social capital are able to benefit with greater ease than those poor in terms of such resources. As more people look towards crowdfunding and its platforms become crowded, this problem is only likely to increase, as those with greater resources are better equipped to differentiate themselves and stand out. Thus as a result those with a higher need for such platforms and fundraising practices may suffer.

While crowdfunding is becoming an increasingly popular form of financing as practitioners seek to circumvent traditional routes to market, as this study shows it should be approached with caution. Crowdfunding requires a greater amount of time, resources and effort than many realise, with work required not just during, but arguably more importantly before a campaign in order to establish many of the structures and drivers identified in this research. When taking this into account we begin to question, despite its hype, whether crowdfunding can in the long-term, provide an effective and viable alternative to more traditional forms of financing. We find that crowdfunding may actually be ineffective and for many only offer a platform that allows creative's to continue to struggle to make their creative work. Whilst crowdfunding will undoubtedly work for some, we argue those with established identity will be able to make it work with far greater ease than those without, which parallels the situation in more traditional forms of financing which crowdfunding is proposed to circumvent.

The data analysed within this study is relatively small and thus future work may consider testing the insight presented against a larger number of campaigns, which would also allow 
consideration of the differences that occur between the 'Film \& Video' subcategories and genres. To our knowledge this is the first paper that analyses campaigns specifically related to filmmaking categories upon reward-based platforms. With the increasing prominence of crowdfunding this study is particularly timely in order to provide practitioners insight, so as to avoid what can be naïve and costly mistakes.

\section{References}

Agrawal, A. K., Catalini, C. and Goldfarb, A. (2011). "The geography of crowdfunding", working paper 16820, National Bureau of Economic Research, Cambridge, USA, 2011.

Agrawal, A. K., Catalini, C. and Goldfarb, A. (2011). "Some Simple Economics of Crowdfunding", working paper 19133, National Bureau of Economic Research, Cambridge, USA, 2013.

Alsteste, J. (2008). "Aspects of entrepreneurial success", Journal of Small Business and Enterprise Development, Vol. 15 No. 3, pp. 584-594.

Baddour, N. (2011). "Indiegogo Insight: Pitch Videos Power Contributions- Increasing Them 114\%", available from: http://go.indiegogo.com/blog/2011/12/indiegogo-insightpitch-videos-power-contributions.html (accessed 3 January 2013).

Baron, R. A. (2008). "The role of affect in the entrepreneurial process", Academy of Management Review, Vol. 33 No. 2, pp. 328-340.

Belleflamme, P., Lambert, T. and Schwienbacher, A. (2012a). "Crowdfunding: tapping the right crowd", working paper, Louvain School of Management, Louvain-la-Neuve, 2012.

Belleflamme, P., Lambert, T. and Schwienbacher, A. (2013). "Individual Crowdfunding Practices", Venture Capital: An International Journal of Entrepreneurial Finance, Vol. 15 No. 4, pp. 313-333.

Berglin, H. and Strandberg, C. (2013). "Leveraging customers as investors: The driving forces behind crowdfunding", Doctoral dissertation, Uppsala University.

Blasco-Arcas, L., Hernandez-Ortega, B. and Jimenez-Martinez, J., (2013). "The online purchase as a context for co-creating experiences. Drivers and consequences for customer behavior", Internet Research, Vol. 24 No. 3, pp. 393-412.

Botti, S. (2000). "What role for marketing in the arts? An analysis of arts consumption and artistic value", International Journal of Arts Management, Vol. 2 No. 3, pp. 14-27.

Boyles, T. (2011). "Small Business and Web 2.0: Hope or Hype?'", The Entrepreneurial Executive, Vol. 16, pp.81-96. 
Brabham, D. C. (2008). "Moving the crowd at iStockphoto: The composition of the crowd and motivations for participation in a crowdsourcing application", First Monday, Vol. 13 No. 6.

Cardon, M. S., Sudek, R. and Mitteness, C. (2009). "The impact of perceived entrepreneurial passion on angel investing", Frontiers of entrepreneurship research, Vol. 29 No. 2, pp. 1-15.

Cardon, M. S., Wincent, J., Singh, J. and Drnovsek, M. (2009). "The nature and experience of entrepreneurial passion", Academy of Management Review, Vol. 34, No. 3, pp. 511532.

Chen, X., Yao, X. and Kotha, S. (2009). "Entrepreneur passion and preparedness in business plan presentations: A persuasion analysis of venture capitalists' funding decisions", Academy of Management Journal, Vol. 52 No. 1, pp. 199-214.

Chiou, J-S., Hsiao, C-C. and Su, F-Y. "Whose online reviews have the most influences on consumers in cultural offerings? Professional vs consumer commentators", Internet Research, Vol. 24 No. 3, pp 353-368

Cohen, J. (2010). "Crowdfunding Myths: "If you Build It they Will Come"", available from: http://rockethub.org/profiles/blogs/crowdfunding-myths-if-you (accessed January 5 2013).

De Buysere, K., Oliver, G., Ronald, K. and Dan, M. (2012). "A Framework for European Crowdfunding." European Crowdfunding Network Report

DesMarais, C. (2013). "5 tips for running a successful crowdfunding campaign", available from: http://www.pcworld.com/article/2033468/5-tips-for-running-a-successfulcrowdsourcing-campaign.html (accessed 28 June 2013).

Durkin, M. and McGowan, P. (2013). "Exploring social media adoption in small to mediumsized enterprises in Ireland", Journal of Small Business and Enterprise Development, Vol. 20, No. 4, pp. 716-734.

Elsbach, K. D. and Kramer, R. M. (2003). "Assessing creativity in Hollywood pitch meetings: Evidence for a dual-process model of creativity judgments", The Academy of Management Journal, Vol. 46 No. 3 pp. 283-301.

Fabrigar L., Wegener, D., MacCallum R. and Strahan, E. (1999). "Evaluating the issue of exploratory factor analysis in psychological research", Psychological Methods, Vol. 4 No. 3, pp. 272-99.

Fournier, S. and Lee, L.(2009). "Getting brand communities right", Harvard business review, Vol. 87 No. 4, pp. 105-111.

Franco, M., Santos, M. D. F., Ramalho, I. and Nunes, C. (2014). "An exploratory study of entrepreneurial marketing in SMEs: The role of the founder-entrepreneur", Journal of Small Business and Enterprise Development, Vol. 21 No. 2, pp. 266-283. 
Gerber, E. M., Hui, J. S. and Kuo, P. (2012). "Crowdfunding: Why people are motivated to post and fund projects on crowdfunding platforms", paper presented at The 2012 ACM Conference on Computer Supported Cooperative Work, Seattle, USA, available from: http://www.juliehui.org/wpcontent/uploads/2013/04/CSCW_Crowdfunding_Final.pdf (accessed 4 May 2013)

Hollis, A. and Sweetman, A. (2001). "The life-cycle of a microfinance institution: The Irish loan funds", Journal of economic behavior \& organization, Vol. 46 No. 3, pp. 291311.

Howe, J. (2006). "The Rise of Crowdsourcing", available from: http://www.wired.com/wired/archive/14.06/crowds.html (accessed 19 November 2012).

Howe, J. (2009). How the Power of the Crowd is Driving the Future of Business, Random House Business, London.

Hsu, C-L., Lin J, C-C. and Chiang, H-S., (2012). "The effects of blogger recommendations on customers' online shopping intentions", Internet Research, Vol. 23 No. 1, pp. 6988 .

Hsu, M-H., Chuang, L-W. and Hs, C-S., (2014). "Understanding online shopping intention: the roles of four types of trust and their antecendents", Internet Research, Vol. 24 No. 3, pp. 332-352

Hui, J. S., Gerber, E. and Greenberg, M. (2012). "Easy Money? The Demands of Crowdfunding Work", Segal Technical Report, Vol. 12 No. 4.

Hussain, J., Millman, C. and Matlay, H. (2006). "SME financing in the UK and in China: a comparative perspective", Journal of Small Business and Enterprise Development, Vol. 13 No. 4, pp. 584-599.

Jenkins, H., Ford, S., and Green, J. (2013). Spreadable media: Creating value and meaning in a networked culture, New York University Press, New York.

Kenny, R. and Broughton, T. (2011). "Securing the Future of UK Animation”, Animation UK, London

Kickstarter. (2012a). "Kickstarter School", available from: http://www.kickstarter.com/help/school (accessed 15 December 2012).

Kickstarter. (2012b). "OUYA: A New Kind of Video Game Console", available from: https://www.kickstarter.com/projects/ouya/ouya-a-new-kind-of-video-game-console (accessed 15 December 2012

Kickstarter. (2013). "Kickstarter Stats", available from: http://www.kickstarter.com/help/stats (accessed 30 January 2013). 
Kuppuswamy, V. and Bayus, B. L. (2013). "Crowdfunding Creative Ideas: The Dynamics of Project Backers in Kickstarter", working paper, Kenan-Flager Business School, North Carolina, USA, 2013.

Labovitz, E. (2010). "Indiegogo Insight: Campaigns that send 11 or more updates, raise $137 \%$ more money", available from: http://blog.indiegogo.com/2010/11/indiegogo-insightif-you-send-updates-they-will-fund.html (accessed 13 January 2013).

MacManus, C. (2013). "Dark truth about Ouya debut: Retail wins, Kickstarter loses", available from: http://news.cnet.com/8301-17938_105-57590930-1/dark-truth-aboutouya-debut-retail-wins-kickstarter-loses/ (accessed 26 June 2013)

Markowitz, E. (2013). "When Kickstarter Investors Want Their Money Back", available from: http://www.inc.com/eric-markowitz/when-kickstarter-investors-want-theirmoney-back.html (accessed 10 January 2013).

Massolution. (2012). "Crowdfunding Industry Report", Crowdsourcing LLC, New York.

Merton, R.K. (1968). "The Matthew Effect In Science", Science, Vol. 159, pp. 56-63.

Molina-Morales, F.X. and Martinez-Fernandez, M.T. (2010). "Social Networks: Effects of Social Capital on Firm Innovation", Journal of Small Business Management, Vol. 48 No. 2, pp. 258-279.

Mollick, E. (2012). "The Dynamics of Crowdfunding: Determinants of Success and Failure", Journal of Business Venturing, Vol. 29 No. 1, pp. 1-16.

Nielsen, J. (2006). "Participation Inequality: Encouraging More Users to Contribute", available at: http://www.nngroup.com/articles/participation-inequality/ (accessed 5 January 2013).

Novak, T.P. and Hoffman, D.L. (2000). "Advertising and Pricing Models for the Web", in Hurley, D., Kahin B. and H.Varian. (Eds), Internet Publishing and Beyond: The Economics of Digital Information and Intellectual Property, MIT Press, Cambridge, USA, pp. 45-62.

Peltier, J.W. and Naidu, G.M. (2012)."Social networks across the SME organizational lifecycle", Journal of Small Business and Enterprise Development, Vol. 19 No. 1, pp. 56-73.

Pi, J. (2012) "The Untold Story Behind Kickstarter Stats" available from: http://www.appsblogger.com/behind-kickstarter-crowdfunding-stats/ (accessed 24 May 2013).

Pirolo, L. and Presutti, M. (2010). "The Impact of Social Capital on the Start-ups' Performance Growth", Journal of Small Business Management, Vol. 48 No. 2, pp. 197-227. 
Powell, S. and Dodd, C. (2007) "Managing vision and the brand within the creative industries", Corporate Communications: An International Journal, Vol. 12 No. 4, pp. 394-413.

Prahalad, C.K. and Ramaswamy, V. (2004). "Co- creation experiences: The next practice in value creation", Journal of interactive marketing, Vol. 18 No. 3, pp. 5-14.

RocketHub. (2013). "Prepare to Launch." available from: http://www.rockethub.com/education/launch (accessed 28 June 2013).

RocketHub. (2011). "Crowdfunding Manifesto." available from: http://rockethub.org/page/manifesto-strategy (accessed 11 December 2012).

Schau, H.J., Muniz, A.M. Jr. and Arnould E.J. (2009). "How brand community practices create value", Journal of Marketing, Vol. 73 No. 5, pp. 30-51.

Scholz, T. (2012). "Introduction: Why Does Dgital Labor Matter Now", in Scholz, T. (Ed) Digital Labor: The Internet as Playground and Factory, Routledge, London, pp. 111.

Seghers, A., Manigart S. and Vanacker, T. (2012). "The Impact of Human and Social Capital on Entrepreneurs' Knowledge of Finance Alternatives", Journal of Small Business Management, Vol. 50 No.1, pp. 63-86.

Shao, G., (2009). "Understanding the appeal of user-generated media: a uses and gratification perspective", Internet Research, Vol. 19. No. 1, pp. 7-25.

Sigmund, S., Semrau T. and Wegner, D. (2013). "Networking Ability and the Financial Performance of New Ventures: Moderating Effects of Venture Size, Institutional Environment, and Their Interaction", Journal of Small Business Management, available from:

http://onlinelibrary.wiley.com/store/10.1111/jsbm.12009/asset/jsbm12009.pdf? (accessed 22 April 2014).

Steinberg, S. M. and DeMaria, R. (2012). The Crowdfunding Bible: How to Raise Money for Any Startup, Video Game Or Project. Read Me.

Thorpe, Devin. (2012). "4 Crowdfunding Mistakes for Social Entrepreneurs to Avoid" available from: http://www.forbes.com/sites/devinthorpe/2012/12/05/4crowdfunding-mistakes-for-social-entrepreneurs-to-avoid/ (accessed 1 January 2013)

Tucker, J. and Lean, J. (2003). "Small firm finance and public policy", Journal of Small Business and Enterprise Development, Vol. 10, No. 1, pp. 50-61

Ward, C. and Ramachandran, V. (2010). "Crowdfunding the next hit: Microfunding online experience goods", paper presented at the Workshop on Computational Social Science and the Wisdom of Crowds at NIPS2010, Vancouver, Canada, available from: https://people.cs.umass.edu/ wallach/workshops/nips2010css/papers/ward.pdf (accessed 3 January 2013) 
Wesley, S., LeHew, M. and Woodside, A. G. (2006). "Consumer decision-making styles and mall shopping behavior: Building theory using exploratory data analysis and the comparative method", Journal of Business Research, Vol. 59, No. 5, pp. 535-548.

Xu, A., Yang, X., Rao, H., Huang S. W., Fu, W.T. and Bailey B.P. (2010). "Show Me The Money: An Analysis of Project Updates during Crowdfunding Campaigns", In proceedings of the $32^{\text {nd }}$ annual ACM conference on Human factors in computing systems, Toronto, Canada, pp. 591-600 
